\title{
DEFORMATION ANALYSIS OF LAYERED REINFORCED CONCRETE - FOAM CONCRETE FLOOR SLABS
}

\author{
OKSANA LYTVYNIAK
}

\author{
Lviv Polytechnic National University, Department of Civil Safety, 12 S. Bandery Str., 79013 Lviv, Ukraine \\ correspondence: lytvyniak.oksana@gmail.com
}

\begin{abstract}
This article presents a theoretical study of a stress-strain state of layered reinforced concrete - foam concrete floor slabs (hereinafter called as the LRFCS), with the use of a deformation analysis. Compressive and tensile diagrams of the foam concrete, a tensile diagram of the reinforced concrete and compressive and tensile diagrams of the reinforcement rod are used for the estimation of the stress-strain state of the calculated cross-section of the LRFCS. It should be noted that this article presents the deformation method of loading by the scheme of pure bending for the LRFCS. This deformation method of loading is determined by six shapes of the stress-strain state. These shapes of the stress-strain state are represented by the corresponding distribution diagrams of the relative deformations and the distribution diagrams of internal stresses in the calculated cross-section of the floor slab. Also, this article presents the corresponding equilibrium equations of internal efforts and moments, which act in the calculated cross-section of the floor slab for all shapes of its stress-strain state. Consequently, the mentioned recommendations and mathematical dependencies allow to evaluate the stress-strain state of the LRFCS from its initial loading to its destruction.
\end{abstract}

KEYwords: Stress-strain state, deformation analysis, floor slab, foam concrete, normal concrete, reinforcement rod, distribution diagram of relative deformations, layered reinforced concrete - foam concrete floor slab.

\section{INTRODUCTION}

The different methods of calculation for the bending building structures were changing depending on the achievement of science and technology. Linear and deformation analyses are the most widespread methods of calculation to estimate a stress-strain state of the bending building structures. These calculation methods have positive and negative features.

A linear analysis, which works by the Hook's law, is used to determine the bearing capacity of a bending structure. This analysis is also used during the design of standard buildings [1, 2]. For example, the limit equilibrium method is one of the types of linear analyses of bending building structures. The guidelines of the limit equilibrium method characterize the behaviour of the bending element in the limit stage sufficiently well. However, this method does not allow to make conclusions about the behaviour of the bending element in all stages of the loading, in other words, from «zero» to its destruction. The evaluation of the behaviour of the bending element from the initial load to its destruction can be carried out with the use of a deformation analysis [3, 4]. This analysis allows to understand the structural behaviour of structures in the serviceability and ultimate limit states [5, 6]. The deformation analysis allows to simulate the behaviour of the structure from the initial load to its destruction based on the deformation diagrams of the material.

The standards [7-11] present the detailed methods and recommendations for the design of reinforced concrete structures with the use of a deformation analysis. Moreover, most of the investigations are directed to the calculation reinforced concrete structures [12] and these studies present new approaches to determine the behaviour of these structures under the loading, such as the nonlinear behaviour of beam elements of structural concrete, subjected to asymmetric bending [13], an enhanced method for the nonlinear structural analysis based on the direct energy principles [14, the estimation of ductility in reinforced concrete beams [15], etc.

However, the design of new building structures combining the structural materials with an evaluation of different physical-mechanical properties demands a realization of calculations, which allow to evaluate these structures by the regulated indices. A type of such structures is the LRFCS. These floor slabs are formed from two layers of concrete with a reinforcement (fig. 11).

The lower layer of the LRFCS is formed from normal concrete (its strength quality is $22 \ldots 25 \mathrm{~N} / \mathrm{mm}^{2}$ ). The upper layer of the LRFCS is produced from non-autoclave foam concrete (density of foamed concrete is $900 \mathrm{~kg} / \mathrm{m}^{3}$ or $\left.1000 \mathrm{~kg} / \mathrm{m}^{3}\right)$. The non-autoclave foam concrete is produced at the construction site. The reinforcement of the LRFCS is a spatial reinforcement frame in the shape of a prism. One lateral face of this prism has three longitudinal reinforcement rods and it is located in the lower layer of the normal concrete. These 


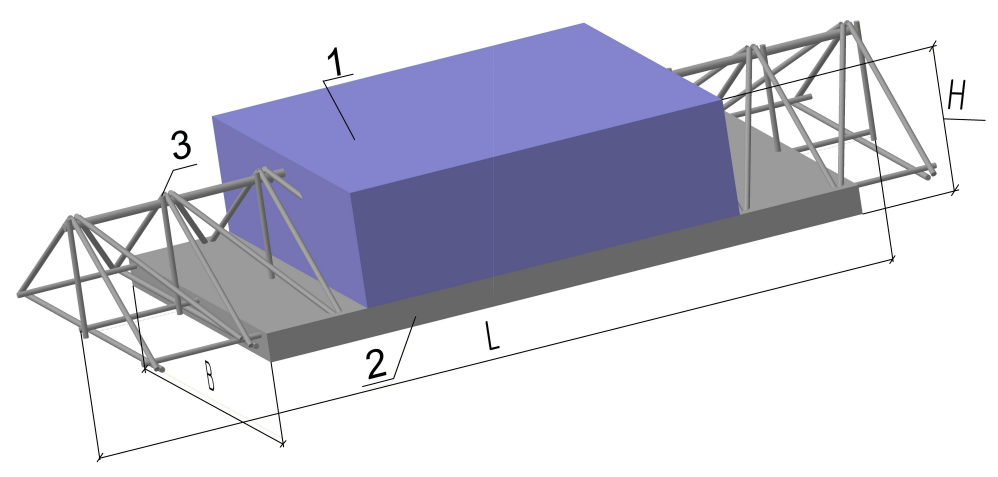

FiguRE 1. Layered reinforced concrete - foam concrete floor slab: 1 - upper layer of non-autoclave foam concrete (its height is $160 \mathrm{~mm}$ ); 2 - lower layer of normal concrete (its height is $40 \mathrm{~mm}$ ); 3 spatial reinforcement frame; $L=4200 \mathrm{~mm}$ or $L=2100 \mathrm{~mm}$ - lengths of the floor slab; $B=500 \mathrm{~mm}$ - the width of the floor slab; $H=200 \mathrm{~mm}-$ the height of the floor slab.

three longitudinal reinforcement rods of the spatial reinforcement frame are joined among themselves by means of transverse reinforcement rods with a formation of a rectangular or triangular grids. The LRFCS has a small mass. Moreover, the lower layers of normal concrete with spatial reinforcement frames are recommended to use as decking. The use of a continuous layer of non-autoclave foam concrete allows to get rid of the use of the autoclave treatment and it excludes the possibility of a shrinkage cracks creation in the upper layer of the foam concrete. The reinforcement of the LRFCS by the spatial reinforcement frame ensures a sufficient strength and rigidity for the entire floor slab of the building. Besides, this spatial reinforcement frame combines upper and lower layers of the floor slab and it ensures that the floor slab behaves as a single bearing component. The use of such structural elements as the normal concrete, spatial reinforcement frame, and non-autoclave foam concrete allows to reduce the financial expenditure of the floor slab of a construction [16, 17.

The calculation methods, which adequately represent and evaluate the stress-strain state of the calculated cross-section of the LRFCS during its loading by the bending, are practically absent. However, the design regulations and design rules, which are presented in normative documents [7-10], can describe the directions of the study concerning their adaptation in new methods. These methods are based on the deformation diagrams of constituent materials taking into account the nature of external loading and a succession of the change of relative deformations in the entire rectangular cross-section of the LRFCS. Such methods will ensure not only the exact appreciation of the limiting state of the LRFCS, but they will also allow us to receive a sufficiently full picture of the consistent development of the stress-strain state of the LRFCS. Besides that, they allow to carry out an evaluation of the bearing capacity for these the LRFCS during all deformation periods of the bending.

\section{MATERIALS AND METHODS}

The theoretical study of the resistance of the LRFCS by an external load is proposed to be carried out based on a method, which is based on the use of the deformation analysis. Moreover, the design of this deformation model is based on distribution diagrams of relative deformations and distribution diagrams of internal stress in the calculated cross-section of the LRFCS.

The distribution diagram of relative deformations in the calculated cross-section is accepted linear for each of the constituent materials of the LRFCS. In other words, it is accepted that the cross-sections of the LRFCS stay planar during the process of deformation. Therefore, the values of relative fibre deformations along the calculated cross-section of the LRFCS are combined with the crookedness of the floor slab in a directly proportional dependence.

The compressive and tensile diagrams of foam concrete, the tensile diagram of reinforced concrete, and the compressive and tensile diagrams of the reinforcement rod must be used for the calculation of the bearing capacity of the LRFCS with the use of the deformation analysis and the evaluation of the stress-strain state of the calculated cross-section of the LRFCS. The mentioned diagrams correspond to the short-term loading, and they determine the connection between the stresses and relative deformations (fig. 2] [18].

The distribution diagrams of internal stresses in the calculated cross-section of the LRFCS are accepted according to the state diagrams "relative deformations - stresses". These diagrams were received during the tests on the single-axis compression (single-axis tension) or pure bending of models of normal concrete, non-autoclave foam concrete, and reinforcement rods.

It is worth to be noted that the stress-strain state of normal concrete's layer in a tensile stage is represented by a bilinear distribution diagram of stresses. The layer of the non-autoclave foam concrete in the compressive 

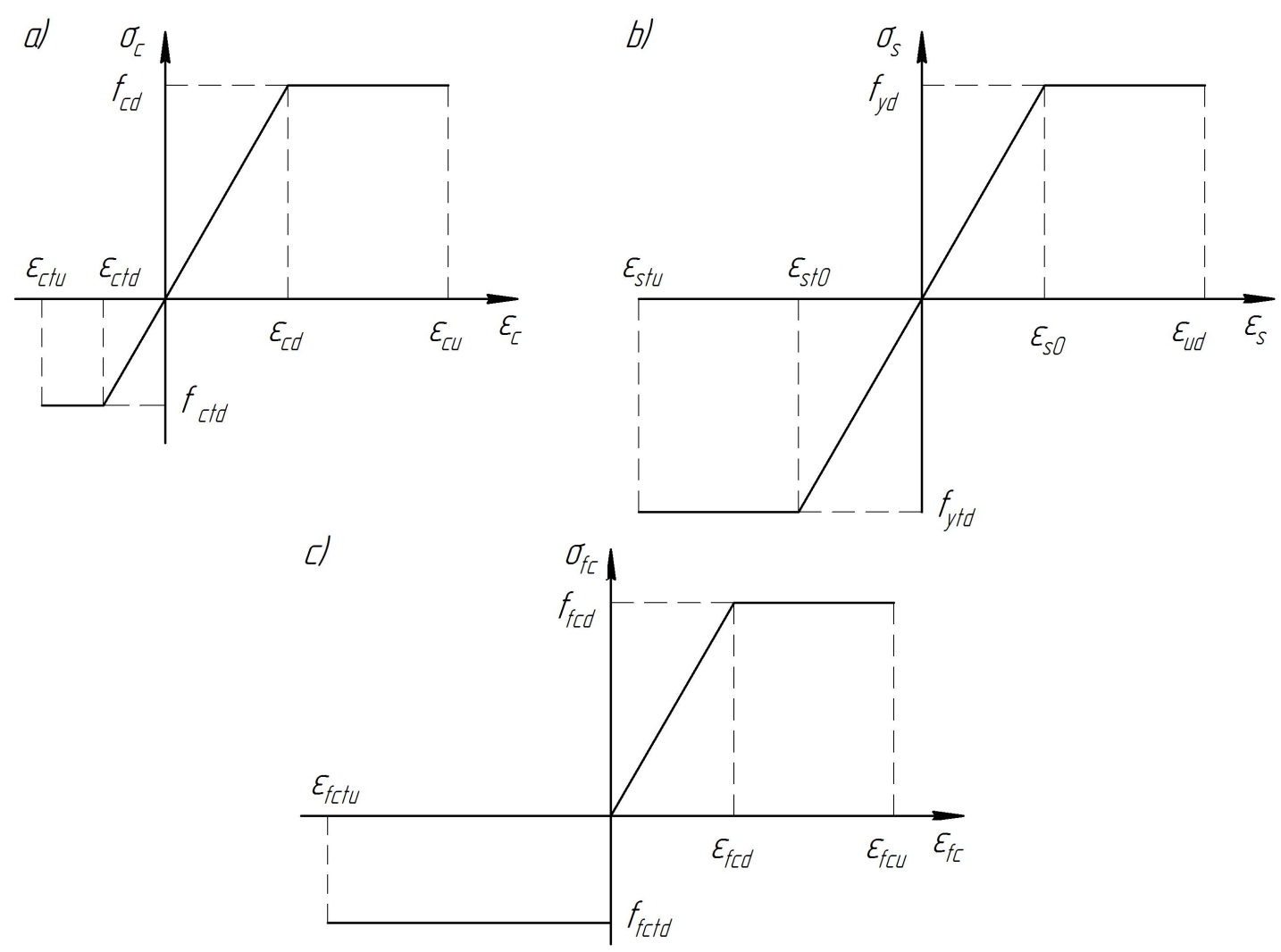

Figure 2. The state diagrams of normal concrete (a), reinforcement (b) and non-autoclave foam concrete (c) 18.

stage is presented by a bilinear distribution diagram of stress. The layer of the non-autoclave foam concrete in the tensile stage is represented by a rectangular distribution diagram of stress [19]. The rules, which are presented in [7, 8], confirm the appropriateness of this supposition. The standards [7, 8] allow using both nonlinear deformation diagrams and bilinear diagrams of reinforcement and normal concrete.

The bilinear state diagram of normal concrete (fig. 2, a) determines the relation between its compressive stresses, tensile stresses, and relative deformations, and, of course, it is described by dependencies by [8]:

$$
\begin{array}{cc}
0 \leq \varepsilon_{c} \leq \varepsilon_{c d}, & \sigma_{c}=E_{c} \cdot \varepsilon_{c} ; \\
\varepsilon_{c d} \leq \varepsilon_{c} \leq \varepsilon_{c u}, & \sigma_{c}=f_{c d} . \\
0 \geq-\varepsilon_{c t} \geq-\varepsilon_{c t d}, & \\
-\varepsilon_{c t d} \geq-\varepsilon_{c t} \geq-\varepsilon_{c t u}, & \sigma_{c t}=E_{c} \cdot\left(-\varepsilon_{c t}\right) ;
\end{array}
$$

$\varepsilon_{c d}$ - relative compressive deformation of normal concrete under corresponding compressive strength of normal concrete; $\varepsilon_{c u}$ - relative compressive deformation limit of normal concrete; $E_{c}$ - modulus of elasticity of normal concrete; $f_{c d}$ - compressive strength of normal concrete; $\varepsilon_{c t d}$ - relative tensile deformation of normal concrete under corresponding tensile strength of normal concrete, which corresponds to the limit of tensile elasticity of normal concrete; $\varepsilon_{c t u}$ - limit relative tensile deformation of normal concrete; $f_{c t d}$ - strength of normal concrete on axial tension.

The relative deformations $\varepsilon_{c d}, \varepsilon_{c t d}$ and $\varepsilon_{c t u}$ are determined by the dependencies:

$$
\begin{aligned}
\varepsilon_{c d} & =\frac{f_{c d}}{E_{c}} \\
\varepsilon_{c t d} & =\frac{f_{c t d}}{E_{c}} \\
\varepsilon_{c t u} & =\frac{2 \cdot f_{c t d}}{E_{c}} .
\end{aligned}
$$

During the calculation of the LRFCS, the state deformation diagram of the reinforcement, which determines the relation between the stresses $\sigma_{s}$ and relative deformations $\varepsilon_{s}$, is accepted as a bilinear diagram. The state diagram of the reinforcement during the compression and tension is accepted as identical [8]. 


\begin{tabular}{|c|c|c|}
\hline $\begin{array}{l}\text { The values of relative } \\
\text { deformations, compressive } \\
\text { strengths and tensile } \\
\text { strengths, and modulus } \\
\text { of elasticity }\end{array}$ & $\begin{array}{l}\text { Layered reinforced concrete } \\
\text { - foam concrete floor slabs } \\
\text { (LRFCS - 1) } \\
\text { (density of foamed concrete } \\
\text { is } 900 \mathrm{~kg} / \mathrm{m}^{3} \text { ) }\end{array}$ & $\begin{array}{l}\text { Layered reinforced concrete } \\
\text { foam concrete floor slabs } \\
\text { (LRFCS - 2) } \\
\text { (density of foamed concrete } \\
\text { is } 1000 \mathrm{~kg} / \mathrm{m}^{3} \text { ) }\end{array}$ \\
\hline$\varepsilon_{c t d}$ & 0.00007350602673 & 0.00006081275062 \\
\hline$\varepsilon_{c t u}$ & 0.0001470120535 & 0.0001216255012 \\
\hline$\varepsilon_{c d}$ & 0.000898989899 & 0.00006068313953 \\
\hline$\varepsilon_{c u}$ & 0.0035 & 0.0035 \\
\hline$E_{c}$ & $25.74 \cdot 10^{3} \mathrm{MPa}$ & $27.52 \cdot 10^{3} \mathrm{MPa}$ \\
\hline$f_{c t d}$ & $1.89 \mathrm{MPa}$ & $1.67 \mathrm{MPa}$ \\
\hline$f_{c d}$ & $23.14 \mathrm{MPa}$ & $19.25 \mathrm{MPa}$ \\
\hline$\varepsilon_{s 0}$ & 0.001610571429 & 0.001660190476 \\
\hline$\varepsilon_{u d}$ & 0.025 & 0.025 \\
\hline$E_{s}$ & $2.1 \cdot 10^{5} \mathrm{MPa}$ & $2.1 \cdot 10^{5} \mathrm{MPa}$ \\
\hline$f_{y d}$ & $338.22 \mathrm{MPa}$ & $348.65 \mathrm{MPa}$ \\
\hline$\varepsilon_{f c d}$ & 0.001 & 0.0008867735471 \\
\hline$\varepsilon_{f c u}$ & 0.0028 & 0.00411 \\
\hline$\varepsilon_{f c t u}$ & 0.0003042253522 & 0.0002585170340 \\
\hline$f_{f c d}$ & $1.42 \mathrm{MPa}$ & $1.77 \mathrm{MPa}$ \\
\hline$f_{f c t d}$ & $0.216 \mathrm{MPa}$ & $0.258 \mathrm{MPa}$ \\
\hline$E_{f c}$ & $1.42 \cdot 10^{3} \mathrm{MPa}$ & $1.996 \cdot 10^{3} \mathrm{MPa}$ \\
\hline
\end{tabular}

TABLE 1. The values of relative deformations, compressive strengths and tensile strengths, and modulus of elasticity for normal concrete, reinforcement, and non-autoclave foam concrete.

The stresses in reinforcement $\sigma_{s}$ are determined depending on relative deformations according to the state diagram of the reinforcement (fig. 2, b) [8]:

$$
\begin{array}{lr}
0 \leq \varepsilon_{s} \leq \varepsilon_{s 0}, & \sigma_{s}=E_{s} \cdot \varepsilon_{s} \\
\varepsilon_{s 0} \leq \varepsilon_{s} \leq \varepsilon_{u d}, & \sigma_{s}=f_{y d}
\end{array}
$$

$\varepsilon_{s 0}$ - relative deformation of the extension of the reinforcement, when the stresses achieve the calculated tensile resistance of the reinforcement rod; $\varepsilon_{u d}$ - relative limit deformation of the extension of the reinforcement rod; $E_{s}$ - modulus of elasticity of the reinforcement rod; $f_{y d}$ - strength of the reinforcement rod at the yield stress.

The relative deformation of extension for the reinforcement is proposed to be calculated by the formula: $\varepsilon_{s 0}=\frac{f_{y d}}{E_{s}}$.

The stress-strain state of non-autoclave foam concrete is accepted as a bilinear state diagram according to the recommendations, which are presented in [7-10. This bilinear state diagram of non-autoclave foam concrete (fig. 2 c) should be determined by the ratios:

$$
\begin{array}{lr}
0 \leq \varepsilon_{f c} \leq \varepsilon_{f c d}, & \sigma_{f c}=E_{f c} \cdot \varepsilon_{f c} \\
\varepsilon_{f c d} \leq \varepsilon_{f c} \leq \varepsilon_{f c u}, & \sigma_{f c}=f_{f c d} .
\end{array}
$$

$\varepsilon_{f c d}$ - relative compressive deformation of non-autoclave foam concrete under the corresponding compressive strength of non-autoclave foam concrete; $\varepsilon_{f c u}$ - relative limit compressive deformation of non-autoclave foam concrete; $E_{f c}$ - modulus of elasticity of non-autoclave foam concrete; $f_{f c f}$ - compressive strength of non-autoclave foam concrete.

The relative compressive deformations of non-autoclave foam concrete $\varepsilon_{f c d}$ and relative tensile deformations of non-autoclave foam concrete $\varepsilon_{f c t u}$ should be determined by the formulas [18]:

$$
\varepsilon_{f c d}=\frac{f_{f c d}}{E_{f c}} ; \quad \quad \varepsilon_{f c t u}=-\frac{2 \cdot f_{f c t d}}{E_{f c}} .
$$

The values of $\varepsilon_{c t d}, \varepsilon_{c t u}, \varepsilon_{c d}, \varepsilon_{c u}, E_{c}, f_{c t d}, f_{c d}, \varepsilon_{s 0}, \varepsilon_{u d}, E_{s}, f_{y d}, \varepsilon_{f c d}, \varepsilon_{f c u}, \varepsilon_{f c t u}, f_{f c d}, f_{f c t d}, E_{f c}$ (they were obtained during experimental studies [16, 18]), which were used during the calculation of the stress-strain state of the LRFCS with the use of the deformation analysis, are shown in table 1.

The bearing capacity of the LRFCS during the action of bending moment should be determined by the following preconditions $[8]$ : 
- as the calculated cross-section, the averaged cross-section that corresponds to mean deformations of nonautoclave foam concrete, normal concrete, and reinforcement on along the length of the block between cracks, if these cracks are present, is accepted;

- the deformations in reinforcement are identical with deformations of non-autoclave foam concrete during its compression and with deformations of normal concrete during its tension;

- the linear law of strain distribution is true for the calculated cross-section of LRFCS;

- the connection between the stresses and deformations of normal concrete, the reinforcement rod, and non-autoclave foam concrete is accepted based on the state diagrams of corresponding materials (fig. 2);

- the reinforcement rods do not have their own moment of inertia, i.e. they are absolutely flexible.

\section{Results and Discussion}

The process of loading of the LRFCS by the scheme of pure bending passes through several shapes of stress-strain state (fig. 3). These shapes are described by corresponding distribution diagrams of stresses in the calculated cross-section.

Accepted diagrams of dependencies of the stresses from relative deformations along the height of the calculated cross-section are different for different materials, which are acted upon by the load (non-autoclave foam concrete, reinforcement, normal concrete), and for different conditions of their work (elasticity, plasticity and crack formation).

The criteria of the loss of bearing capacity of the LRFCS are [7, 8]:

- the loss of equilibrium between internal and external forces (reaching the maximum on diagrams «momentcrookedness $\gg)$;

- the destruction of compressed foam concrete by fibre deformations when reaching the limit values $\varepsilon_{f c u}$ or the break of all stretched reinforcement rods as a consequence of reaching the limit deformations $\varepsilon s u d$ in these reinforcement rods.

The stress-strain state of the calculated cross-section is represented by internal forces. They are resultant forces of tensile stresses or compressive stresses that are perceived by corresponding layers of non-autoclave foam concrete, normal concrete, and upper and lower reinforcement rods. Moreover, these forces appear as a consequence of created relative deformations from the action of external moment $M$ in the calculated cross-section.

The calculation of the stress-strain state of the LRFCS is represented by six shapes of equilibrium. These shapes are characterized by the corresponding equilibrium equations of internal forces and moments that act in the calculated cross-section (fig. 3).

The first shape of equilibrium (fig. 3, c). The total distribution diagram of stresses in the calculated cross-section of the LRFCS is formed by a diagram of compressive stresses of foam concrete (triangular shape), a diagram of tensile stresses of foam concrete (rectangular shape), a diagram of tensile stresses of normal concrete (not full triangular shape), compressive stresses of the reinforcement in the upper layer and tensile stresses of the reinforcement in the lower layer. The compressive stresses of foam concrete occupy the height of the compression area $x$ of the calculated cross-section.

It is necessary to write down a system of equilibrium equations of internal forces of the stress-strain state of the LRFCS for the first shape of equilibrium, taking into account the joint work of materials in the calculated cross-section. This system of equations is composed of the equation that defines the value of bending moment $M$ acting on the LRFCS. Besides that, this system of equations is determined by the relatively neutral axis of the moments' sum of corresponding internal forces, and the equation of the sum of projections of internal forces $\sum_{i} N_{i}=0$ on the longitudinal axis of the LRFCS.

$$
\begin{aligned}
\frac{b \cdot h \cdot E_{f c} \cdot \varepsilon_{f c 1}^{2}}{2\left(\varepsilon_{f c 1}+\varepsilon_{c t 2}\right)}- & b \cdot f_{f c t d} \cdot\left(Z_{C 1}-\frac{\varepsilon_{f c 1} \cdot h}{\varepsilon_{f c 1}+\varepsilon_{c t 2}}\right)- \\
& -\frac{b \cdot E_{c}}{2 h} \cdot\left(\varepsilon_{f c 1}+\varepsilon_{c t 2}\right) \cdot\left(\left(h-\frac{\varepsilon_{f c 1} \cdot h}{\varepsilon_{f c 1}+\varepsilon_{c t 2}}\right)^{2}-\left(Z_{C 1}-\frac{\varepsilon_{f c 1} \cdot h}{\varepsilon_{f c 1}+\varepsilon_{c t 2}}\right)^{2}\right)+ \\
& +\frac{\left(\varepsilon_{f c 1}+\varepsilon_{c t 2}\right) \cdot E_{S}}{h} \cdot\left(\left(\frac{\varepsilon_{f c 1} \cdot h}{\varepsilon_{f c 1}+\varepsilon_{c t 2}}-Z_{S 1}\right) \cdot A_{S 1}-\left(Z_{S 2}-\frac{\varepsilon_{f c 1} \cdot h}{\varepsilon_{f c 1}+\varepsilon_{c t 2}}\right) \cdot A_{S 2}\right)=0 .
\end{aligned}
$$



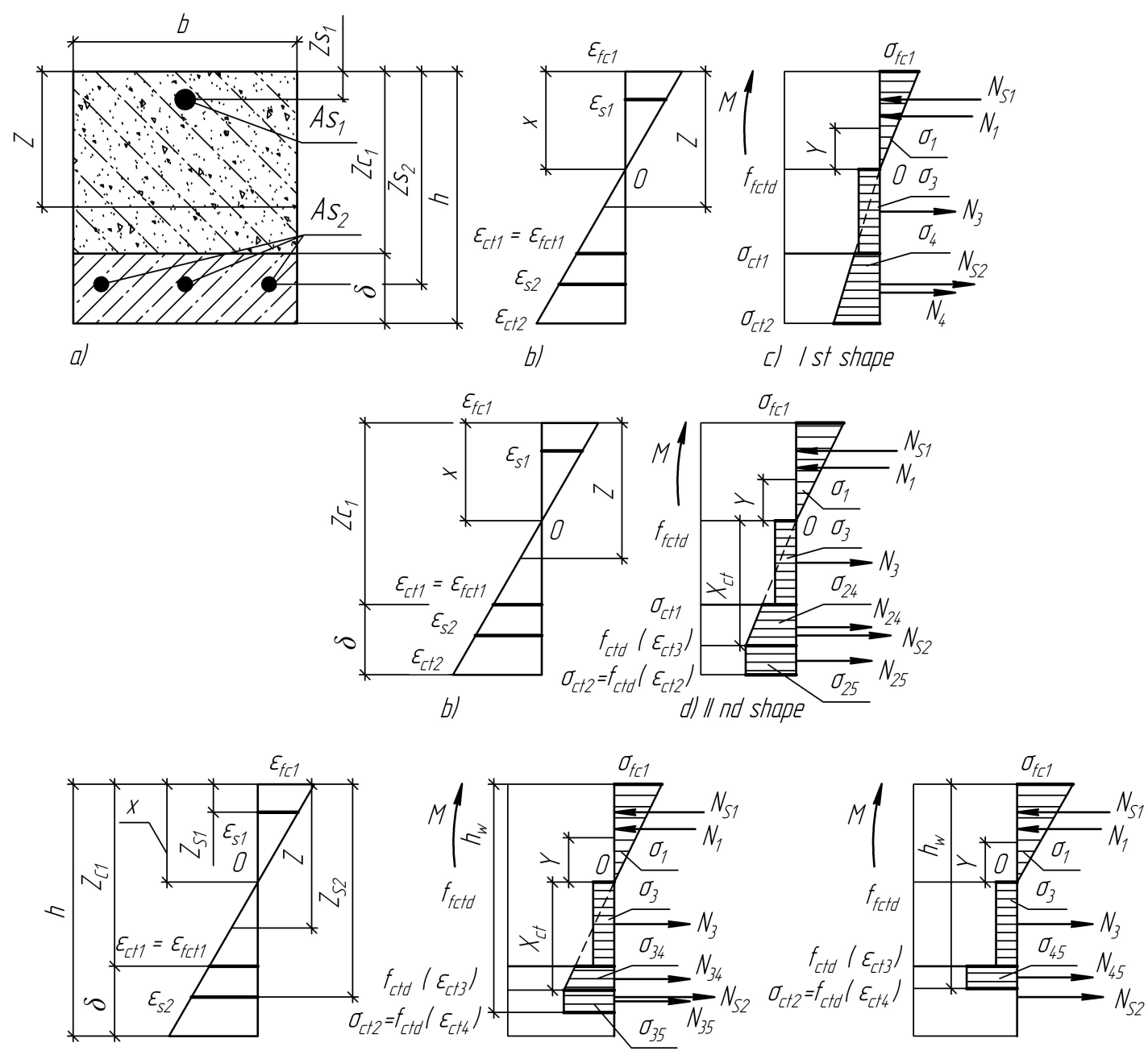

e)

f) III rd shape

g) IV th shape
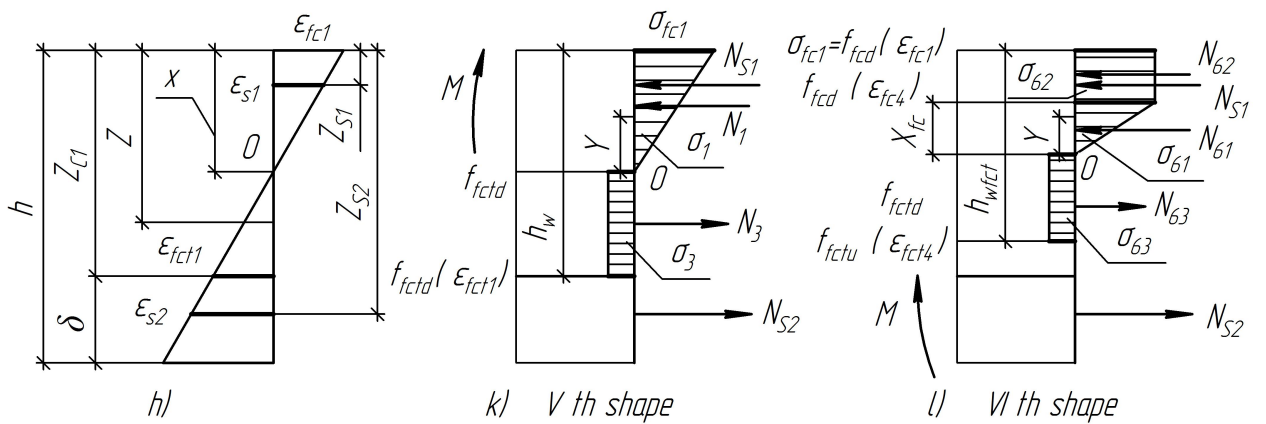

FIgURE 3. The stress-strain state of layered reinforced concrete - foam concrete floor slab (rectangular cross-section with double reinforcement): a) cross-section; b), e), h) - strain diagrams; c), d), f), g), r), l) - stress diagrams by the shapes of equilibrium. 


$$
\begin{array}{r}
M=\frac{1}{3} \cdot b \cdot \frac{\varepsilon_{f c 1}+\varepsilon_{c t 2}}{h} \cdot E_{f c} \cdot\left(\frac{\varepsilon_{f c 1} \cdot h}{\varepsilon_{f c 1}+\varepsilon_{c t 2}}\right)^{3}+\frac{1}{2} \cdot b \cdot f_{f c t d} \cdot\left(Z_{C 1}-\frac{\varepsilon_{f c 1} \cdot h}{\varepsilon_{f c 1}+\varepsilon_{c t 2}}\right)^{2}+ \\
+\frac{1}{3} \cdot b \cdot \frac{\varepsilon_{f c 1}+\varepsilon_{c t 2}}{h} \cdot E_{c} \cdot\left(\left(h-\frac{\varepsilon_{f c 1} \cdot h}{\varepsilon_{f c 1}+\varepsilon_{c t 2}}\right)^{3}-\left(Z_{C 1}-\frac{\varepsilon_{f c 1} \cdot h}{\varepsilon_{f c 1}+\varepsilon_{c t 2}}\right)^{3}\right)+ \\
+E_{S} \cdot \frac{\varepsilon_{f c 1}+\varepsilon_{c t 2}}{h} \cdot\left(\left(\frac{\varepsilon_{f c 1} \cdot h}{\varepsilon_{f c 1}+\varepsilon_{c t 2}}-Z_{S 1}\right)^{2} \cdot A_{S 1}+\left(Z_{S 2}-\frac{\varepsilon_{f c 1} \cdot h}{\varepsilon_{f c 1}+\varepsilon_{c t 2}}\right)^{2} \cdot A_{S 2}\right) .
\end{array}
$$

The corresponding values of relative deformations $\varepsilon_{f c 1}$ on the upper limit of the compressed foam concrete are determined in an accordance with the prescribed values of relative deformations $\varepsilon_{c t 2}$ on the lower limit of tensile normal concrete according to the formula (7). The monotonous increase of deformations $\varepsilon_{c t 2}$ is accepted from the value of deformation $\varepsilon_{c t 2}=0$ to a value of deformation $\varepsilon_{c t d}$ (deformation of the elastic limit of tensile normal concrete), i.e. $\varepsilon_{c t 2}=\varepsilon_{c t d}$. The last value $\varepsilon_{c t 2}$ corresponds to the stress-strain state of the cross-section of the LRFCS, under which the not-fully-triangular shape of the stress diagram of tension for normal concrete transforms into the bilinear shape of the stress diagram of tension for normal concrete. This shape combines the not-fully-triangular diagram for the stresses of normal concrete in conditions of elasticity and a rectangular diagram for the stresses of normal concrete in conditions of plasticity.

An analysis of the equation of projections of internal forces on the longitudinal axis of the LRFCS allows us to establish that it is possible to determine the corresponding values $\varepsilon_{f c 1}$ by changing the values $\varepsilon_{c t 2}$. On the contrary, this same equation allows us to determine the deformations $\varepsilon_{c t 2}$ for the exchangeable deformations $\varepsilon_{f c 1}$. In other words, this represents some flexibility of this deformation analysis in the choice of variable, which is determined.

The second shape of equilibrium (fig. 3, d). The total distribution diagram of stresses in the calculated cross-section of the LRFCS combines the compressive stresses of foam concrete (triangular shape), the tensile stresses of foam concrete (rectangular shape), the tensile stresses of the normal concrete (triangular and rectangular shapes), the compressive stresses of the reinforcement in the upper layer and tensile stresses of the reinforcement in the lower layer. The compressive stresses of foam concrete occupy the height of the compression area $x$ of the calculated cross-section.

The compressive stresses $\sigma_{1}$ and tensile stresses $\sigma_{3}$ in the layer of foam concrete, and also compressive stresses $\sigma_{S 1}$ and tensile stresses $\sigma_{S 2}$ in the reinforcement rods, corresponding resultants of internal forces $N_{1}$, $N_{3}, N_{S 1}, N_{S 2}$ and moments of these forces concerning neutral line $M_{1}, M_{3}, M_{S 1}, M_{S 2}$ are determined the same as for the first shape of the equilibrium (fig. 3 , d).

The tensile stresses $\sigma_{c t 2}$ in the layer of normal concrete are described by a bilinear diagram for the second shape of the equilibrium. This diagram consists of a not-fully-triangular part and the rectangular part. The full triangular part corresponds to the elastic state of the behaviour of normal concrete. The rectangular part corresponds to the plastic state with the stress of plasticity that is equal to the calculated tensile strength of normal concrete $f_{c t d}$. The elastic limit of tensile normal concrete is located at a distance $X_{c t}$, i.e. at the distance from zero line to level, in which the ultimate stress of elasticity arises.

The equation of the sum of projections of internal forces on the longitudinal axis of the LRFCS and the equation for the determination of the outer bending moment $M$ for the second shape of the equilibrium are shown in equations $(9)$ and 10 :

$$
\begin{aligned}
& \frac{1}{2} \cdot b \cdot \frac{h \cdot \varepsilon_{f c 1}^{2}}{\varepsilon_{f c 1}+\varepsilon_{c t 2}} E_{f c}-b \cdot f_{f c t d} \cdot\left(Z_{C 1}-\frac{\varepsilon_{f c 1} \cdot h}{\varepsilon_{f c 1}+\varepsilon_{c t 2}}\right)- \\
&-\frac{1}{2} \cdot b \cdot \frac{\varepsilon_{f c 1}+\varepsilon_{c t 2}}{h} \cdot E_{c} \cdot\left(\frac{\varepsilon_{c t d}^{2} \cdot h^{2}}{\left(\varepsilon_{f c 1}+\varepsilon_{c t 2}\right)^{2}}-\left(Z_{C 1}-\frac{\varepsilon_{f c 1} \cdot h}{\varepsilon_{f c 1}+\varepsilon_{c t 2}}\right)^{2}\right)- \\
&-b \cdot f_{c t d} \cdot h \cdot\left(1-\frac{\varepsilon_{c t d}}{\varepsilon_{f c 1}+\varepsilon_{c t 2}}-\frac{\varepsilon_{f c 1}}{\varepsilon_{f c 1}+\varepsilon_{c t 2}}\right)+E_{S} \cdot \frac{\varepsilon_{f c 1}+\varepsilon_{c t 2}}{h} \cdot\left(\frac{\varepsilon_{f c 1} \cdot h}{\varepsilon_{f c 1}+\varepsilon_{c t 2}}-Z_{S 1}\right) \cdot A_{S 1}- \\
&-E_{S} \cdot \frac{\varepsilon_{f c 1}+\varepsilon_{c t 2}}{h} \cdot\left(Z_{S 2}-\frac{\varepsilon_{f c 1} \cdot h}{\varepsilon_{f c 1}+\varepsilon_{c t 2}}\right) \cdot A_{S 2}=0
\end{aligned}
$$




$$
\begin{gathered}
M=\frac{1}{3} \cdot b \cdot \frac{\varepsilon_{f c 1}^{3} \cdot h^{2}}{\left(\varepsilon_{f c 1}+\varepsilon_{c t 2}\right)^{2}} \cdot E_{f c}+\frac{1}{2} \cdot b \cdot f_{f c t d} \cdot\left(Z_{C 1}-\frac{\varepsilon_{f c 1} \cdot h}{\varepsilon_{f c 1}+\varepsilon_{c t 2}}\right)^{2}+ \\
\quad+\frac{1}{3} \cdot b \cdot \frac{\left(\varepsilon_{f c 1}+\varepsilon_{c t 2}\right)}{h} \cdot E_{c} \cdot\left(\frac{\varepsilon_{c t d}^{3} \cdot h^{3}}{\left(\varepsilon_{f c 1}+\varepsilon_{c t 2}\right)^{3}}-\left(Z_{C 1}-\frac{\varepsilon_{f c 1} \cdot h}{\varepsilon_{f c 1}+\varepsilon_{c t 2}}\right)^{3}+\right. \\
+\frac{1}{2} \cdot b \cdot f_{c t d} \cdot\left(\left(h-\frac{\varepsilon_{f c 1} \cdot h}{\varepsilon_{f c 1}+\varepsilon_{c t 2}}\right)^{2}-\frac{\varepsilon_{c t d}^{2} \cdot h^{2}}{\left(\varepsilon_{f c 1}+\varepsilon_{c t 2}\right)^{2}}\right)+E_{s} \cdot \frac{\left(\varepsilon_{f c 1}+\varepsilon_{c t 2}\right)}{h} \cdot\left(\frac{\varepsilon_{f c 1} \cdot h}{\varepsilon_{f c 1}+\varepsilon_{c t 2}}-Z_{S 1}\right)^{2} \cdot A_{S 1}+ \\
+E_{s} \cdot \frac{\left(\varepsilon_{f c 1}+\varepsilon_{c t 2}\right)}{h} \cdot\left(Z_{S 2}-\frac{\varepsilon_{f c 1} \cdot h}{\varepsilon_{f c 1}+\varepsilon_{c t 2}}\right)^{2} \cdot A_{S 2} \cdot(10)
\end{gathered}
$$

When the compressive deformations $\varepsilon_{f c 1}$ (on the upper compressed fibre of foam concrete) increase and, correspondingly, the tensile deformations $\varepsilon_{f c t 1}$ (on the lower tensile fibre of foam concrete) grow, then the deformations $\varepsilon_{c t 3}$ reach the value of tensile deformations of normal concrete, which are equal to the values of the tensile deformation of normal concrete under corresponding tensile strength of normal concrete, that corresponds to the limit of tensile elasticity of normal concrete, that is $\varepsilon_{c t 3}=\varepsilon_{c t d}$.

The third shape of equilibrium (fig. 3, f). The compressive stresses $\sigma_{1}$ and the tensile stresses $\sigma_{3}$ along the height of the calculated cross-section of the LRFCS in the layer of non-autoclaved foam concrete correspond to the distribution diagrams of stresses, which are similar to the distribution diagrams of stresses that are used for the first and the second shapes of the equilibrium.

The stress distribution in tensile normal concrete is subordinate to the bilinear stress diagram. It is formed of a not-fully-triangular shape and the rectangular shape. The not-fully-triangular shape corresponds to the stress distribution in normal concrete, which does not exceed its elastic limit on tension $f_{c t d}$. The rectangular shape corresponds to such stress distribution of tension under which the stresses are equal to only the calculated tensile strength of normal concrete $f_{c t d}$ in each fibre of tensile normal concrete. In this case, relative deformations in this fibre should exceed a deformation at the calculated tensile strength of normal concrete $\varepsilon_{\text {ctd }}$ and they should be less than the limit deformation of tensile normal concrete $\varepsilon_{c t u}$. The fibre, in which the deformation is equal to $\varepsilon_{c t d}$, should be located at a distance $X_{c t}$ from the zero line.

When the compressive deformation $\varepsilon_{f c 1}$ (on the upper compressed fibre of foam concrete) and tensile deformation $\varepsilon_{f c t 1}$ (on the lower tensile fibre of foam concrete) increase, then the formation of a crack on the lower side of normal concrete happens. The apex of this crack is located at a distance $h_{w}$ from the upper side of the LRFCS. This process is followed by the diminution of the height of the calculated cross-section. The gradual displacement of the elastic limit and strength limit to the limit of the contact between a tensile layer of foam concrete and a tensile layer of normal concrete is observed as a consequence of an increase of tensile deformations in the layer of normal concrete. The stress of elasticity gradually changes to the stress of plasticity $f_{c t d}$ for tensile normal concrete.

The strength limit in tensile normal concrete is determined by the fibre, in which the deformation $\varepsilon_{c t 4}$ is equal to the ultimate strain of tension $\varepsilon_{c t u}$.

The equation of the sum of projections of internal forces on the longitudinal axis of the LRFCS and the equation for the determination of the outer bending moment $M$ for the third shape of equilibrium are shown in equations 11 and 12 :

$$
\begin{aligned}
& \frac{b}{2} \cdot \frac{Z_{C 1} \cdot E_{f c} \cdot \varepsilon_{f c 1}^{2}}{\varepsilon_{f c 1}+}-\varepsilon_{c t 1} \\
& \quad-\frac{b}{2} \cdot \frac{\varepsilon_{f c 1}+\varepsilon_{c t 1}}{Z_{C 1} \cdot\left(\varepsilon_{f c 1}+\varepsilon_{c t 1}\right)^{2}} \cdot E_{c 1} \cdot\left(1-\frac{\varepsilon_{f c 1}}{\varepsilon_{f c 1}+\varepsilon_{c t 1}}\right)- \\
& \left.\left.\quad+E_{S}{ }^{2} \cdot A_{S 1} \cdot\left(\varepsilon_{c t d}^{2}-\varepsilon_{c t 1}^{2}\right)-\frac{b \cdot f_{c t d} \cdot Z_{C 1}}{\varepsilon_{f c 1}+\varepsilon_{c t 1}} \cdot\left(\varepsilon_{f c 1}+\varepsilon_{c t u}\right) \cdot \frac{Z_{S 1}}{Z_{C 1}}\right)-E_{c t d}\right)+ \\
& \quad E_{S} \cdot A_{S 2} \cdot\left(\frac{Z_{S 2}}{Z_{C 1}} \cdot\left(\varepsilon_{f c 1}+\varepsilon_{c t 1}\right)-\varepsilon_{f c 1}\right)=0
\end{aligned}
$$

$$
\begin{aligned}
M=\frac{1}{3} \cdot b \cdot \frac{\varepsilon_{f c 1}^{3} \cdot Z_{C 1}{ }^{2} \cdot E_{f c}}{\left(\varepsilon_{f c 1}+\varepsilon_{c t 1}\right)^{2}}+\frac{1}{2} \cdot b \cdot f_{f c t d} \cdot Z_{C 1}{ }^{2} \cdot\left(1-\frac{\varepsilon_{f c 1}}{\varepsilon_{f c 1}+\varepsilon_{c t 1}}\right)^{2}+ \\
\quad+\frac{1}{3} \cdot \frac{b \cdot E_{c} \cdot Z_{C 1}{ }^{2}}{\left(\varepsilon_{f c 1}+\varepsilon_{c t 1}\right)^{2}} \cdot\left(\varepsilon_{c t d}^{3}-\varepsilon_{c t 1}^{3}\right)+\frac{1}{2} \frac{b \cdot f_{c t d} \cdot Z_{C 1}^{2}}{\left(\varepsilon_{f c 1}+\varepsilon_{c t 1}\right)^{2}} \cdot\left(\varepsilon_{c t u}^{2}-\varepsilon_{c t d}^{2}\right)+
\end{aligned}
$$




$$
\begin{aligned}
& +E_{s} \cdot\left(\varepsilon_{f c 1}+\varepsilon_{c t 1}\right) \cdot Z_{C 1} \cdot A_{S 1} \cdot\left(\frac{\varepsilon_{f c 1}}{\varepsilon_{f c 1}+\varepsilon_{c t 1}}-\frac{Z_{S 1}}{Z_{C 1}}\right)^{2}+ \\
& \quad+E_{s} \cdot\left(\varepsilon_{f c 1}+\varepsilon_{c t 1}\right) \cdot Z_{C 1} \cdot A_{S 2} \cdot\left(\frac{Z_{S 2}}{Z_{C 1}}-\frac{\varepsilon_{f c 1}}{\varepsilon_{f c 1}+\varepsilon_{c t 1}}\right)^{2}
\end{aligned}
$$

The value of deformation $\varepsilon_{c t 1}$ on the upper tensile border of normal concrete (it is in a direct contact with a layer of tensile foam concrete) is determined from the equation (11) with the use of the change of the value of deformation $\varepsilon_{f c 1}$ (in fixed limits) on the upper fibre of compressed foam concrete. After that, an outer bending moment $M$, which is acting on the LRFCS, is calculated from the equation (12). It should be noted that, when we substitute the well-known value $\varepsilon_{c t 1}=\varepsilon_{c t d}$ in equation (11), we can calculate the value of the deformation $\varepsilon_{f c 1}$ on the upper compressive fibre of foam concrete. During these calculations, the deformation $\varepsilon_{f c 1}$ is increasing as long as the value of the deformation is equal to the limit deformation $\varepsilon_{c t d}\left(\varepsilon_{c t 1}=\varepsilon_{c t d}\right)$. And, of course, the stresses on the border of layers of normal concrete and foam concrete should be equal to the calculated tensile strength of normal concrete - $f_{c t d}$. With this ratio of deformations, the bilinear distribution diagram of tensile stress in a layer of normal concrete transforms into the rectangular diagram. In other words, the third shape of equilibrium (fig. 3 f) changes into the fourth shape of equilibrium (fig. $3 . \mathrm{g}$ ).

The fourth shape of equilibrium (fig. 3, g). Compressive stresses and tensile stresses in the layer of non-autoclave foam concrete, and also compressive stresses and tensile stresses in the reinforcement, are distributed along the height of the calculated cross-section similarly as for the first shape of equilibrium. The stress, which acts in the layer of normal concrete, is equal to the calculated tensile concrete strength $f_{c t d}$, i.e. $\sigma_{45}=f_{c t d}$ (the distribution diagram of tensile stresses is of a rectangular shape).

A crack is in the layer of tensile normal concrete. The apex of this crack is located at the distance $h_{w}$ from the upper fibre of the LRFCS. The relative deformation $\varepsilon_{c t 4}$ is located in the fibre, where the apex of the crack is. This deformation $\varepsilon_{c t 4}$ reaches the value of the relative limit tensile deformation of normal concrete $\varepsilon_{c t u}$, in other words, the equation 12 is realized.

The equation of the sum of projections of internal forces on the longitudinal axis of the LRFCS and the equation for the determination of the outer bending moment $M$ for the fourth shape of equilibrium are presented in equations $(13)$ and $(14)$ :

$$
\begin{array}{r}
\frac{b}{2} \cdot \frac{Z_{C 1} \cdot E_{f c} \cdot \varepsilon_{f c 1}^{2}}{\varepsilon_{f c 1}+\varepsilon_{c t 1}}-b \cdot f_{f c t d} \cdot Z_{C 1} \cdot\left(1-\frac{\varepsilon_{f c 1}}{\varepsilon_{f c 1}+\varepsilon_{c t 1}}\right)- \\
-\frac{b \cdot f_{c t d} \cdot Z_{C 1}}{\varepsilon_{f c 1}+\varepsilon_{c t 1}} \cdot\left(\varepsilon_{c t u}-\varepsilon_{c t 1}\right)+E_{S} \cdot A_{S 1} \cdot\left(\varepsilon_{f c 1}-\left(\varepsilon_{f c 1}+\varepsilon_{c t 1}\right) \cdot \frac{Z_{S 1}}{Z_{C 1}}\right)- \\
\quad-E_{S} \cdot A_{S 2} \cdot\left(\frac{Z_{S 2}}{Z_{C 1}} \cdot\left(\varepsilon_{f c 1}+\varepsilon_{c t 1}\right)-\varepsilon_{f c 1}\right)=0
\end{array}
$$

$$
\begin{aligned}
& M= \frac{1}{3} \cdot b \cdot \frac{\varepsilon_{f c 1}^{3} \cdot Z_{C 1}^{2} \cdot E_{f c}}{\left(\varepsilon_{f c 1}+\varepsilon_{c t 1}\right)^{2}}+\frac{1}{2} \cdot b \cdot f_{f c t d} \cdot Z_{C 1}^{2} \cdot\left(1-\frac{\varepsilon_{f c 1}}{\varepsilon_{f c 1}+\varepsilon_{c t 1}}\right)^{2}+ \\
&+\frac{1}{2} \frac{b \cdot f_{c t d} \cdot Z_{C 1}^{2}}{\left(\varepsilon_{f c 1}+\varepsilon_{c t 1}\right)^{2}} \cdot\left(\varepsilon_{c t u}^{2}-\left(1-\varepsilon_{f c 1}\right)^{2}\right)+E_{s} \cdot\left(\varepsilon_{f c 1}+\varepsilon_{c t 1}\right) \cdot Z_{C 1} \cdot A_{S 1} \cdot\left(\frac{\varepsilon_{f c 1}}{\varepsilon_{f c 1}+\varepsilon_{c t 1}}-\frac{Z_{S 1}}{Z_{C 1}}\right)^{2}+ \\
& \quad+E_{s} \cdot\left(\varepsilon_{f c 1}+\varepsilon_{c t 1}\right) \cdot Z_{C 1} \cdot A_{S 2} \cdot\left(\frac{Z_{S 2}}{Z_{C 1}}-\frac{\varepsilon_{f c 1}}{\varepsilon_{f c 1}+\varepsilon_{c t 1}}\right)^{2}
\end{aligned}
$$

The determination of necessary deformations for the fourth shape of equilibrium is carried out taking into account the limits of deformations $\varepsilon_{c t 1}$ for the upper fibre of tensile normal concrete. The initial limit of the change of the deformation is the deformation $\varepsilon_{c t 1}$, which is equal to the deformation $\varepsilon_{c t d}$ that corresponds to the calculated tensile strength of normal concrete $f_{c t d}$, i.e. $\varepsilon_{c t 1}=\varepsilon_{c t d}$. The final limit of the change of the deformation $\varepsilon_{c t 1}$ is the limit deformation $\varepsilon_{c t u}$, i.e. $\varepsilon_{c t 1}=\varepsilon_{c t u}$. In other words, the deformation $\varepsilon_{c t 1}$ (on the upper fibre of tensile normal concrete) is equal to the limit tensile deformation of normal concrete $\varepsilon_{c t u}$, at which the apex of the crack reaches the upper border of the layer of tensile normal concrete.

When compressive deformations $\varepsilon_{f c 1}$ and tensile deformations $\varepsilon_{f c t 1}$ increase, then the deformations $\varepsilon_{c t 3}$ also increase. This process is accompanied by a gradual displacement of the border of the relative limit deformation of tensile normal concrete $\varepsilon_{c t u}$ to the upper border of the layer of tensile normal concrete that is located at the distance $Z_{C 1}$. Then, deformations on border «normal concrete - foam concrete» become equal to $\varepsilon_{c t 1}=\varepsilon_{f c t 1}=\varepsilon_{c t 3}=\varepsilon_{c t u}$. 
In consequence, the layer of normal concrete is completely cut off by the crack and it is completely excluded from the work concerning the perception of the outer bending moment. Therefore, the fourth shape of equilibrium (fig. 3. g) transforms into the fifth shape of equilibrium (fig. 3 , k).

The fifth shape of equilibrium (fig. 3, k). The layer of normal concrete in the calculated cross-section does not experience the bending moment, since it is completely cut off by the crack. The spread boundary of the crack is at the border «normal concrete - foam concrete». The apex of this boundary is located at the distance $h_{w}$ from the upper fibre of the LRFCS and it establishes the real height of the calculated cross-section, i.e. $h_{w}=Z_{C 1}$.

The outer loading is perceived only by the layer of compressive foam concrete, the layer of tensile foam concrete, and the compressive and tensile reinforcement.

The compressive deformations $\varepsilon_{f c 1}$ (on the upper fibre of compressed foam concrete) and the tensile deformations $\varepsilon_{f c t 1}$ (on the lower fibre of tensile foam concrete) do not exceed the deformations for the calculated values of the compressive strength of foam concrete $\varepsilon_{f c d}\left(\varepsilon_{f c 1}<\varepsilon_{f c d}\right)$ and the tensile strength of foam concrete $\varepsilon_{f c d}\left(\varepsilon_{f c t 1}<\varepsilon_{f c t d}\right)$. The values of compressive stresses $\sigma_{1}$ and tensile stresses $\sigma_{3}$ in foam concrete is located within the limits $\sigma_{1}<f_{f c d}$ and $\sigma_{3}=f_{f c t d}$.

The stresses $\sigma_{1}$ and $\sigma_{3}$ in the layer of non-autoclaved foam concrete, the stresses in the upper and lower reinforcement $\sigma_{S 1}$ and $\sigma_{S 2}$, and also resultant internal forces $N_{1}, N_{S 1}, N_{S 2}$ and moments $M_{1}, M_{S 1}, M_{S 2}$ are determined by the ratios for the first shape of equilibrium of the calculated cross-section of LRFCS.

The relevant force $N_{3}$ from tensile stresses $\sigma_{3}$ for tensile foam concrete and a corresponding moment $M_{3}$ of this force should be determined by taking into account corresponding limits of integration (from zero to $\left.\left(h_{w}-x\right)\right)$, which are different from the accepted limits for the first shape of equilibrium.

The equilibrium equation for the internal forces $\sum_{i} N_{i}=0$ on the longitudinal axis of the LRFCS and the expression for the determination of the outer bending moment $M$ for the fifth shape of equilibrium are shown in ratios 15 and 16 :

$$
\begin{aligned}
& \frac{b}{2} \cdot \frac{Z_{C 1} \cdot E_{f c} \cdot \varepsilon_{f c 1}^{2}}{\varepsilon_{f c 1}+\varepsilon_{f c t 1}}-b \cdot f_{f c t d} \cdot Z_{C 1} \cdot\left(1-\frac{\varepsilon_{f c 1}}{\varepsilon_{f c 1}+\varepsilon_{f c t 1}}\right)+ \\
& \quad+E_{S} \cdot A_{S 1} \cdot\left(\varepsilon_{f c 1}-\left(\varepsilon_{f c 1}+\varepsilon_{f c t 1}\right) \cdot \frac{Z_{S 1}}{Z_{C 1}}\right)-E_{S} \cdot A_{S 2} \cdot\left(\frac{Z_{S 2}}{Z_{C 1}} \cdot\left(\varepsilon_{f c 1}+\varepsilon_{f c t 1}\right)-\varepsilon_{f c 1}\right)=0 \\
& M=\frac{1}{3} \cdot b \cdot \frac{\varepsilon_{f c 1}^{3} \cdot Z_{C 1}^{2} \cdot E_{f c}}{\left(\varepsilon_{f c 1}+\varepsilon_{f c t 1}\right)^{2}}+\frac{1}{2} \cdot b \cdot f_{f c t d} \cdot Z_{C 1}^{2} \cdot\left(1-\frac{\varepsilon_{f c 1}}{\varepsilon_{f c 1}+\varepsilon_{f c t 1}}\right)^{2}+ \\
& +E_{s} \cdot\left(\varepsilon_{f c 1}+\varepsilon_{f c t 1}\right) \cdot Z_{C 1} \cdot A_{S 1} \cdot\left(\frac{\varepsilon_{f c 1}}{\varepsilon_{f c 1}+\varepsilon_{f c t 1}}-\frac{Z_{S 1}}{Z_{C 1}}\right)^{2}+ \\
& +E_{s} \cdot\left(\varepsilon_{f c 1}+\varepsilon_{f c t 1}\right) \cdot Z_{C 1} \cdot A_{S 2} \cdot\left(\frac{Z_{S 2}}{Z_{C 1}}-\frac{\varepsilon_{f c 1}}{\varepsilon_{f c 1}+\varepsilon_{f c t 1}}\right)^{2} .
\end{aligned}
$$

When the values of deformations in the extreme fibre of tensile foam concrete $\varepsilon_{f c t 1}$ are accepted, then the deformation on the upper fibre of compressed foam concrete $\varepsilon_{f c 1}$ is determined from the equation 15 . After that, the determined numerical values are compared with the value of the limit deformation $\varepsilon_{f c d}$ for the calculated values of the compressive strength of foam concrete.

It was determined that the deformation $\varepsilon_{f c 1}$ is lesser than the deformation $\varepsilon_{f c d}\left(\varepsilon_{f c 1}<\varepsilon_{f c d}\right)$ for a wide range of foam concretes. Besides that, the change of deformations in the extreme tensile fibre of the layer of foam concrete from the deformation $\varepsilon_{f c t 1}=\varepsilon_{f c u}$ until the deformation $\varepsilon_{f c t 1}=\varepsilon_{f c t u}$ corresponds to the limit of the crack formation in tensile normal concrete and foam concrete. In other words, the layer of compressed foam concrete works in the elastic state, namely the Hooke's law is applies. Moreover, the distribution diagram of compressive stresses in the layer of foam concrete is of a triangular form.

This fifth shape of equilibrium for the calculated cross-section remains until the momentm when a triangular distribution diagram of the compression stress in the layer of foam concrete will not become a bilinear distribution diagram of stress. The boundary of this change will be observed when the stresses $\sigma_{f c 1}$ will not reach a value of the calculated compressive strength of foam concrete $f_{f c d}\left(\sigma_{f c 1}=f_{f c d}\right)$ on the extreme upper fibre of compressed foam concrete and the deformation $\varepsilon_{f c 1}$ will be equal to the deformation $\varepsilon_{f c d}$ for the mentioned fibre of foam concrete.

The sixth shape of equilibrium (fig. 3, 1). The distribution of compressive stresses in the layer of compressed foam concrete subordinates the bilinear diagram. The distribution of tensile stress in the layer of tensile foam concrete subordinates the rectangular diagram. 
The stresses in compressed foam concrete are equal $\sigma_{61}=\varepsilon_{f c 2} \cdot E_{f c}=y \cdot \chi \cdot E_{f c}$ and $\sigma_{62}=f_{f c d}$ respectively, for the triangular and rectangular zones of the bilinear distribution diagram of stresses, taking into account the value of the deformation for some fibres.

The stresses in tensile foam concrete $\sigma_{63}$ are distributed along a zone that is confined to the zero line and the annex of the crack. This crack appears in the fibre of tensile foam concrete at the deformation $\varepsilon_{f c t 2}$, which exceeds the value of the limit tensile deformation of foam concrete $\varepsilon_{f c t u}\left(\varepsilon_{f c t 2}>\varepsilon_{f c t u}\right)$. The apex of the crack in the layer of tensile foam concrete is located at the distance $h_{w f c t}$ from the upper fibre of compressed foam concrete with the deformation $\varepsilon_{f c 1}$. For this shape of equilibrium, this size determines the height of the calculated cross-section of the LRFCS on the condition that the outer loading will be experienced by the layer of foam concrete and the reinforcement.

The stresses in tensile foam concrete are equal to $\sigma_{63}=f_{f c t d}$ by the accepted diagram of its distribution on the height of the calculated cross-section.

In the calculated cross-section, the distance $X_{f c}$ is determined by the formula (17):

$$
X_{f c}=\frac{\varepsilon_{f c 2}}{\chi},
$$

$\varepsilon_{f c 2}$ - deformation in the corresponding fibre of compressive foam concrete, which is accepted equal to $\varepsilon_{f c d}$ (i.e., it is equal to the limit deformation that corresponds to the calculated value of the compressive strength of foam concrete $f_{f c d}$ (elastic limit of compressed foam concrete)).

The distance $X_{f c}$ is located from the zero line to the fiber on which the deformation $\varepsilon_{f c 2}$ is equal to the deformation at the calculated value of the compressive strength of foam concrete $\varepsilon_{f c d}$.

The inner efforts $N_{61}, N_{62}, N_{63}$ (acting in the calculated cross-section in the layer of compressed and tensile foam concrete) and also the moments $M_{61}, M_{62}, M_{63}$ are determined, taking account corresponding limits of integration (from zero to $X_{f c}$ ).

The inner efforts $N_{S 1}, N_{S 2}$, as the resultant forces of stresses, which act on the reinforcement rods, and also moments $M_{S 1}, M_{S 2}$ from these efforts relatively zero line are calculated with the use of the corresponding dependencies as for the first shape of equilibrium.

The equation of the sum of projections of the internal forces on the longitudinal axis of the LRFCS (equation (18) ) and the equation for the determination of the outer bending moment $M$, which balances the sum of moments of the inner forces (equation (19)):

$$
\begin{aligned}
& \frac{b}{2} \cdot \frac{Z_{C 1} \cdot E_{f c} \cdot \varepsilon_{f c d}^{2}}{\varepsilon_{f c 1}+}+\frac{b \cdot f_{f c t} \cdot Z_{C 1}}{\varepsilon_{f c 1}+\varepsilon_{f c t 1}} \cdot\left(\varepsilon_{f c 1}-\varepsilon_{f c d}\right)-\frac{b \cdot f_{f c t d} \cdot Z_{C 1} \cdot \varepsilon_{f c t u}}{\varepsilon_{f c 1}+\varepsilon_{f c t 1}}+ \\
& \quad+E_{S} \cdot A_{S 1} \cdot\left(\varepsilon_{f c 1}-\left(\varepsilon_{f c 1}+\varepsilon_{f c t 1}\right) \cdot \frac{Z_{S 1}}{Z_{C 1}}\right)-E_{S} \cdot A_{S 2} \cdot\left(\frac{Z_{S 2}}{Z_{C 1}} \cdot\left(\varepsilon_{f c 1}+\varepsilon_{f c t 1}\right)-\varepsilon_{f c 1}\right)=0 \\
& M=\frac{1}{3} \cdot b \cdot \frac{\varepsilon_{f c d}^{3} \cdot Z_{C 1}{ }^{2} \cdot E_{f c}}{\left(\varepsilon_{f c 1}+\varepsilon_{f c t 1}\right)^{2}+\frac{1}{2} \cdot \frac{b \cdot f_{f c d} \cdot Z_{C 1}^{2}}{\left(\varepsilon_{f c 1}+\varepsilon_{f c t 1}\right)^{2}} \cdot\left(\varepsilon_{f c 1}^{2}-\varepsilon_{f c d}^{2}\right)+} \\
& \quad+\frac{1}{2} \cdot \frac{b \cdot f_{f c t d} \cdot Z_{C 1}^{2} \cdot \varepsilon_{f c t u}^{2}}{\left(\varepsilon_{f c 1}+\varepsilon_{f c t 1}\right)^{2}}+E_{s} \cdot\left(\varepsilon_{f c 1}+\varepsilon_{f c t 1}\right) \cdot Z_{C 1} \cdot A_{S 1} \cdot\left(\frac{\varepsilon_{f c 1}}{\varepsilon_{f c 1}+\varepsilon_{f c t 1}}-\frac{Z_{S 1}}{Z_{C 1}}\right)^{2}+ \\
& \quad+E_{s} \cdot\left(\varepsilon_{f c 1}+\varepsilon_{f c t 1}\right) \cdot Z_{C 1} \cdot A_{S 2} \cdot\left(\frac{Z_{S 2}}{Z_{C 1}}-\frac{\varepsilon_{f c 1}}{\varepsilon_{f c 1}+\varepsilon_{f c t 1}}\right)^{2} .
\end{aligned}
$$

The deformation of the lower fibre of tensile foam concrete $\varepsilon_{f c t 1}$ is determined from the equation 18 with the use of the value of deformation $\varepsilon_{f c 1}$. The deformation $\varepsilon_{f c t 1}$ is calculated nominally to a greater extent since a crack exists at the level of this fibre. Though the flat cross-section hypothesis does not allow to compose other equations, which allow determining such ratios between $h_{w f c t}$ and $Z_{C 1}$.

The calculation of the stress-strain state for the LRFCS with the use of indicated formulas was carried out with the use of the software package MAPLE.

The diagrams «bending moment - crookedness» for the LRFCS, which contain non-autoclaved foam concrete of different designed grades with densities D900 and D1000 (fig. 4 and fig. 5) are drawn taking into account indicated procedures and correlations. Furthermore, the experimental diagrams «bending moment - curvature» for the LRFCS are presented in the fig. 4 and fig. 5 for a comparison of the theoretical and experimental data. The experimental diagrams were obtained after experimental studies, which were described in [16, 18]. The difference between theoretical and experimental moments is $3.46 \%$ (for the LRFCS-1) and $5.1 \%$ (for the LRFCS-2). At the same time, the difference between theoretical and experimental crookedness is $4.61 \%$ (for the LRFCS-1) and $8.47 \%$ (for the LRFCS-2). 


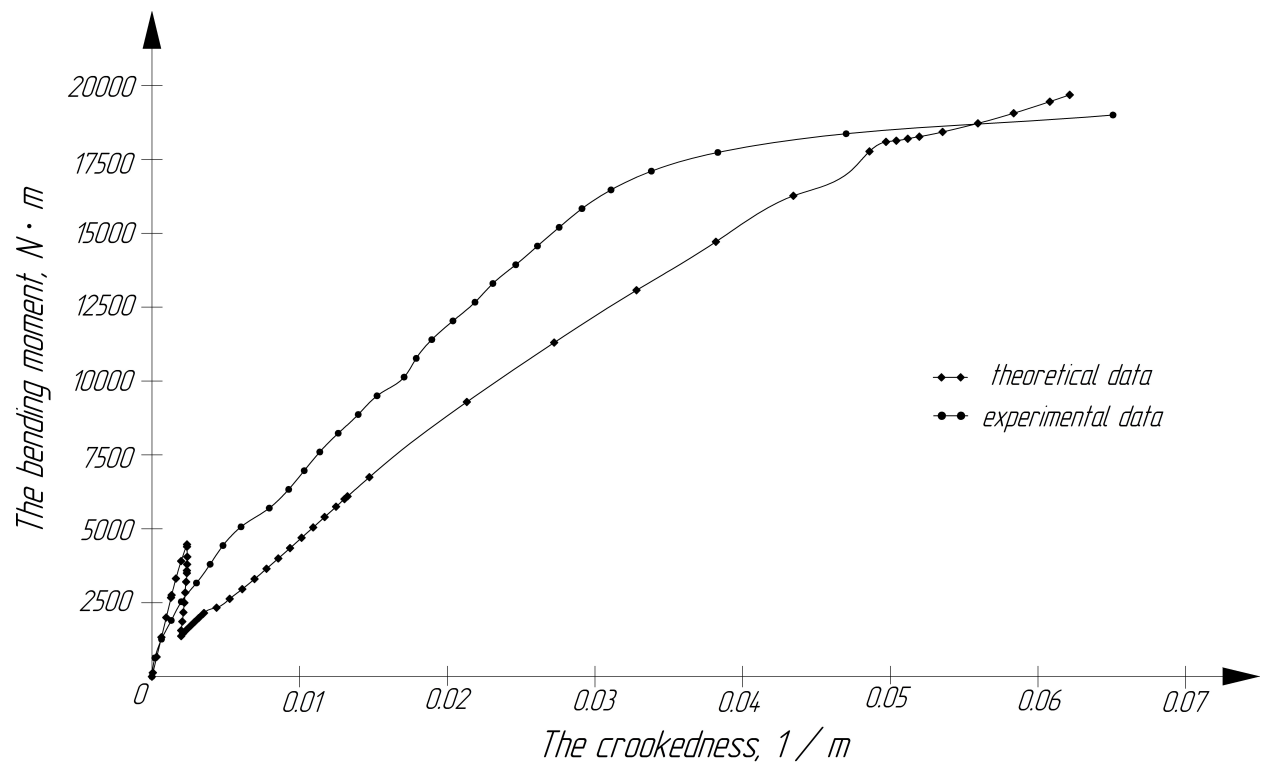

FiguRE 4. Calculated diagrams «bending moment - curvature» for layered reinforced concrete - foam concrete floor slabs LRFCS-1.

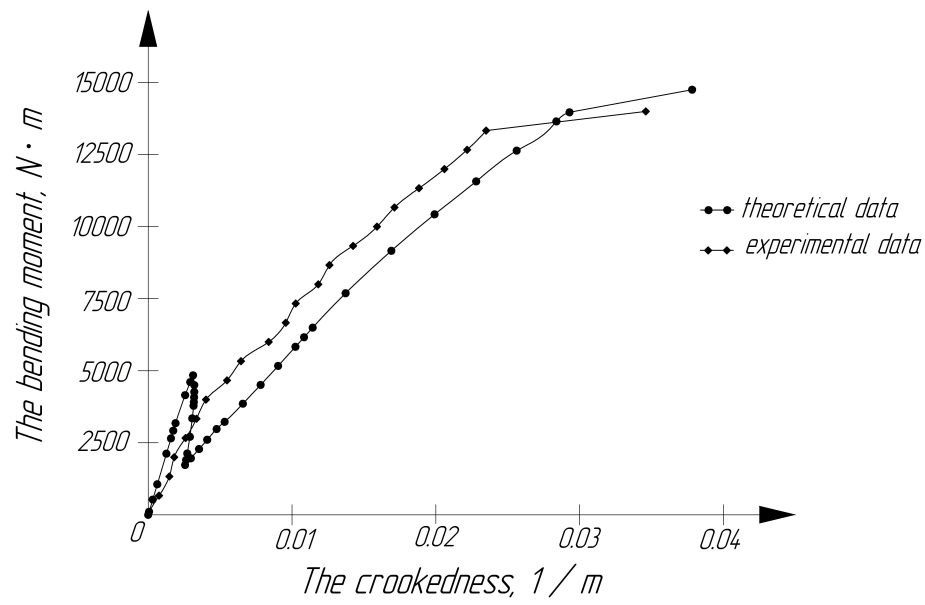

FiguRE 5. Calculated diagrams «bending moment - curvature» for layered reinforced.

The design of theoretical diagrams was carried out on the condition of the priority of deformation's change. The outer force factor (bending moment) was determined by the prescribed value of deformations. This bending moment ensures the balance of inner forces in the calculated cross-section of the LRFCS. Moreover, the diagrams «moment - crookedness» are universal. They allow using the change of the value of bending moment to get values of deformations on the different fibres of the LRFCS and to determine the location of the neutral axis in these floor slabs. And, on the contrary, the change of the values of deformations allows us to get the value of bending moment for the different shapes of stress-strain state for the LRFCS.

In the diagrams «moment - crookedness» (fig. 4. 5), the stresses in the reinforcement increase slowly in the initial loading stage, since the tensile reinforcement and normal concrete experience the tensile forces. Moreover, the diagram «moment - crookedness » (fig. 4. 5 ) on the initial loading stage has a zone, in which the rigidity of the cross-section is higher than for the other zones of loading. This loading stage can be explained by the work of tensile normal concrete. When the formation process of a crack is happening in normal concrete, accordingly, the bending moment suddenly falls, the crookedness of the cross-section suddenly increases and, of course, the stresses in the upper and lower longitudinal reinforcement increase. Further loading leads to an increase of deformations. Besides, the tensile forces pass to the lower longitudinal reinforcement and the bending moment begins to increase, i.e. some «loop» creates [20] (fig. 4, 5). This «loop» characterizes some diminution of the bearing capacity of the LRFCS. Also, further loading of the LRFCS leads to a stabilisation of the rigidity of the cross-section, and it stays practically permanent, similar to the formation of a plastic hinge.

It is worth noting that the deformation method of loading is described in this article because the loading stages were achieved by the increase of the deformations at every shape of the equilibrium. Therefore, the 
decrease of the bending moment and the creation of the so-called «loop» (fig. 4, 5 ) are possible at some stage of the loading. In the case of force loading of the LRFCS, the formation of aforesaid «loop» is not happening [20].

The design of the diagram for the LRFCS («from deformations») ensures receiving additional information about the work of the bending element (floor slab), for example, strength loss, creation of crack, the formation of plastic hinges. Such information is hard to obtain for direct, traditional estimation of the work of the floor slab («from force (moment)»).

The use of the deformation analysis and deformation method of loading for calculation of building structures, especially such structures, which combine building materials with different physical-mechanical properties, allows to determine the «life cycle» of these structures by the different outer factors of influence (deformation or effort). Moreover, it also allows to forecast the «life cycle» of building structures in case of their strengthening or reconstruction.

\section{Conclusions}

The layered reinforced concrete foam concrete floor slabs belong to the class of building multilayer structures, which are not sufficiently studied and for which scientific well-founded design procedures are absent.

The simulation of the stress-strain state for normal cross-sections of layered reinforced concrete - foam concrete floor slabs with the use of a deformation analysis allowed to establish six shapes of equilibrium. The system of two equations was received for each shape of the equilibrium. This system allows to determine the strain distribution along the height of the calculated cross-section for all constructional elements (normal concrete, non-autoclave foam concrete, and reinforcement rod) depending on the value of relative deformations in the upper fibre of the floor slabs. Moreover, the value of the outer moment was determined. This outer moment is acting on the calculated cross-section depending on the crookedness of the layered reinforced concrete - foam concrete floor slab.

Distribution diagrams of the stresses along the height of the calculated cross-section for each of the constructional elements, which were accepted in the deformation analysis, allowed to receive such ratios that allow carrying out the choice of compressive and tensile fibres along the height of the calculated cross-section. And they made possible to establish the corresponding relative deformations, in particular limit deformations. Besides, they allowed receiving the evident dependencies for the determination of relative deformations in other layers. Moreover, this calculation and this simulation allow to ensure the possibility of a flexible analysis for intermediate shapes of the stress-strain state for the layered reinforced concrete - foam concrete floor slabs for the estimation of their work and their behaviour from the initial loading to the destructive loading with a sufficient accuracy.

\section{REFERENCES}

[1] G. K. Çiftci. Nonlinear analysis of reinforced concrete frame structures. Master's thesis, Middle East Technical University, 2013.

[2] P. Grassl, M. Johansson, J. Leppänen. On the numerical modelling of bond for the failure analysis of reinforced concrete. Engineering Fracture Mechanics 189:13 - 26, 2018. DOI:10.1016/j.engfracmech.2017.10.008.

[3] H. Schlune. Safety evaluation of concrete structures with nonlinear analysis. Ph.D. thesis, Chalmers University of Technology, 2011.

[4] D. Milašinović, D. Goleš. Geometric nonlinear analysis of reinforced concrete folded plate structures by the harmonic coupled finite strip method. Periodica Polytechnica Civil Engineering 58(3):173 - 185, 2014. DOI:10.3311/PPci.2096

[5] M. Plos, H. Schlune, K. Gylltoft. Safety formats for non-linear analysis of concrete structures. Magazine of Concrete Research 64(7):563 - 574, 2012. DOI:10.1680/macr.11.00046.

[6] G. Bertagnoli, L. Giordano, G. Mancini. Safety formats for the nonlinear analysis of concrete structures. Studi e ricerche 25. DOI:10.1680/macr.11.00046

[7] DBN V.2.6-98:2009 - Structures of buildings and edifices. Concrete and reinforced concrete structures. Standard, National standard of Ukraine, 2009. In Ukrainian.

[8] DSTU B V.2.6-154:2010 - Structures of buildings and edifices. Concrete and reinforced concrete constructions. Precast and cast-in-situ structures. Design rules. Standard, National standard of Ukraine, 2010. In Ukrainian.

[9] DSTU B V.2.6-156:2010 - Structures of buildings and edifices. Concrete and reinforced concrete constructions. Design rules. Standard, National standard of Ukraine, 2010. In Ukrainian.

[10] BS EN 1992-1-1 - Eurocode 2: Design of concrete structures. General rules and rules for buildings. Standard, British Standards Institution, London, 2004.

[11] M. Knauff. Calculation of reinforced concrete structures according to Eurocode 2. PWN, Warsaw, 2013.

[12] O. Buyukozturk. Nonlinear analysis of reinforced concrete structures. Computers $\&$ Structures 7(1):149 - 156, 1977. DOI:10.1016/0045-7949(77)90069-4 
[13] J. P. M. Xavier, R. L. Pereira, L. J. Pedroso, P. C. R. Martins. Nonlinear analysis of reinforced concrete beams submitted to bending moment gradients considering the variable adhesion model. Journal of the Brazilian Society of Mechanical Sciences and Engineering 42(1):29, 2020.

[14] C. Taube, H.-G. Timmler, G. Morgenthal. Enhanced method for the nonlinear structural analysis based on direct energy principles. Engineering Structures 204:109789, 2020. DOI:10.1016/j.engstruct.2019.109789.

[15] M. Kardala, K. Spiliopoulos. A more realistic estimation of ductility in reinforced concrete beams through threedimensional finite elements. Structural Engineering International 30(1):23 - 32, 2019. DOI:10.14311/AP.2019.59.005

[16] O. Lytvyniak, M. Tashak. The suggestions as to the calculation bearing capacity of sandwich reinforced concrete foamed concrete floor slabs. Acta Polytechnica 59(1):59 - 66, 2019. DOI:10.1080/10168664.2019.1645578.

[17] B. Demchyna, O. Lytvyniak. Patent No. 74425 UA, IPC E04 B5/02, Floor slab of building. patent, 2012.

[18] B. Demchyna, O. Lytvyniak, V. Verba, et al. The non autoclaved foamed concrete structures. Lviv, 2019. In Ukrainian.

[19] The manual by engineering of concrete and reinforced concrete structures of cellular concrete to SNiP 2.03.01-84. Tech. rep., 1985. In Russian.

[20] Y. A. Redykulcev. The calculation of building structures by non linear analysis. 2014. In Russian. 